\title{
Does drug-induced emphysema exist?
}

\author{
Norbert F. Voelkel' ${ }^{1}$, Shiro Mizuno² and Masanori Yasuo ${ }^{3}$
}

Affiliations: ${ }^{1}$ Pulmonary and Critical Care Medicine Division, Virginia Commonwealth University, Richmond, VA, USA. ${ }^{2}$ Division of Pulmonary Medicine, Kanazawa Medical University, Kanazawa, and ${ }^{3}$ First Dept of Internal Medicine, Shinshu University School of Medicine, Matsumoto, Japan.

Correspondence: N.F. Voelkel, Pulmonary and Critical Care Medicine Division, Virginia Commonwealth University, 1220 E Broad St, MMRB 6th floor, Richmond, VA 23298, USA. E-mail: nvoelkelamcvh-vcu.edu

0 @ERSpublications

Mechanisms whereby drugs directly, or in synergism with epigenetic control mechanisms, can destroy lung tissue http://ow.ly/p3n7M

Pulmonary physicians are well aware of drug-induced acute and chronic pulmonary toxicities; inhaled or systemically administered drugs can affect airway tone and cause cough, dyspnoea due to airspace disease, diffuse alveolar damage, pulmonary capillaritis or interstitial lung fibrosis, to name a few presentations and tissue manifestations. Well-studied drugs that cause pulmonary toxicity include methotrexate [1], bleomycin [2] and amiodarone [3], all of which can cause interstitial lung disease, platinum compounds which can generate pulmonary hypersensitivity reactions [4], or propylthiouracil which can cause antineutrophil cytoplasmic antibody positive vasculitis and nonspecific interstitial pneumonitis $[5,6]$. Over the years a catalogue of drug-induced pulmonary toxicities has been assembled [7] and, more recently, druginduced respiratory disease in patients with haematological disorders [8] and toxicity related to the systemic treatment of nonsmall cell lung cancer [9] have been reviewed.

In contrast, repeated PubMed research of the literature did not uncover a single clinical report of druginduced emphysema. This circumstance begs the question whether drugs do not cause toxicities that result in alveolar-capillary cell changes and emphysematous lung parenchyma destruction in humans, or whether drug-induced emphysema is simply not reported.

Herein, we attempt to approach this topic with the appropriate caution, beginning with the statement that on theoretical ground, and based on data derived from animal studies, there ought to be drugs that cause emphysema in susceptible patients. It has been acknowledged that not all of the patients that develop emphysema are smokers; the estimate is that $\sim 15 \%$ of emphysema patients are nonsmokers [10]. Yet pathogenetic mechanisms that can explain emphysema in these patients are lacking after rare associations, like anorexia [11], cadmium exposure [12] or playing a wind instrument, have been ruled out. In the following editorial, we provide a rationale for our postulate of drug-induced emphysema, without speculating that in some cases emphysema in nonsmokers may be drug or diet related.

The traditional concepts applied to explain the pathobiology of emphysematous lung tissue destruction focus on mediators, proteases and reactive oxygen species released from inflammatory cells, all targeting the building blocks of the alveolar structures; mostly epithelial and endothelial cells. In addition, some investigators consider that the alveolar structure cells themselves, for example endothelial cells, become activated and injured without requirement of injurious interactions with inflammatory cells. Regardless, injurious attacks on the alveolar gas exchange units can also be seen in the context of an impaired lung structure maintenance programme $[13,14]$. The adult lung structure maintenance concept integrates genetic and epigenetic control mechanisms, operates with the principle of homeostatic balances, and provides a framework for our understanding of how inflammatory mechanisms are involved in emphysemagenesis. The lung structure maintenance concept also provides room for per se

Received: May 032013 | Accepted after revision: July 292013

Conflict of interest: None declared.

Copyright @ERS 2013 
noninflammatory mechanisms, including drug toxicities. To be clear, the hypothesis of clinically relevant drug-induced emphysema is presently an extrapolation from animal studies; an example of reverse translation.

The first animal data were the results derived from testing the tyrosine kinase/vascular endothelial growth factor (VEGF) receptor inhibitor Sugen 5416, which had emerged from a high throughput screening for compounds that inhibit VEGF-dependent endothelial cell growth [15]. This highly lipophilic small molecule compound was shown to cause significant airspace enlargement in adult rats within 4 weeks after one single subcutaneous injection [16]. At the time the animal experiments were conducted, the consensus was that many lung cell types produce VEGF, while the VEGF receptors were mostly found on the endothelial cells and that VEGF receptor blockade resulted in lung endothelial cell apoptosis. These experiments and the identification of apoptotic lung vessel endothelial cells, in lungs from patients with severe emphysema [17], prepared the way for the hypothesis and discussion of apoptotic cell loss in emphysema $[13,14]$. Later on it became clear that VEGF acts on a large number of lung tissue cells, including alveolar type II cells and vascular smooth muscle cells [17]. The finding of emphysema development as a consequence of treatment with a VEGF receptor-targeting drug were supported by other studies which showed that anti-VEGF antibody treatment [17] or lung-targeted VEGF inactivation in genetically engineered mice [18] generated emphysema. The VEGF receptor/tyrosine kinase inhibitor Su5416 (semaxinib) entered the clinical stage as an anti-angiogenic cancer drug [19,20], but whether any patient treated with semaxinib developed emphysema is unknown, as the survival of cancer patients treated with antiangiogenic therapies is unfortunately short and pulmonary drug toxicities are often only acknowledged as "collateral damage". The c-Jun N-terminal kinase/stress activated protein kinase appears to regulate FGF-induced angiogenesis [21] and may also be involved in the control of VEGF-induced angiogenesis [22]. Mizuno et al. [23] recently demonstrated that inhibition of the focal adhesion kinase resulted in dramatic airspace enlargement, and taken together these reports suggest that drug-induced inhibition of a number of kinase-induced phosphorylation reactions are likely to interfere with angiogenesis and adult lung cell growth (fig. 1).

Iто et al. [24] investigated histone deacetylase (HDAC)-dependent inflammatory gene expression and subsequently examined the lung tissue expression of HDACs in patients with chronic obstructive pulmonary disease (COPD). Although the authors discussed the low expression and activity of HDACs

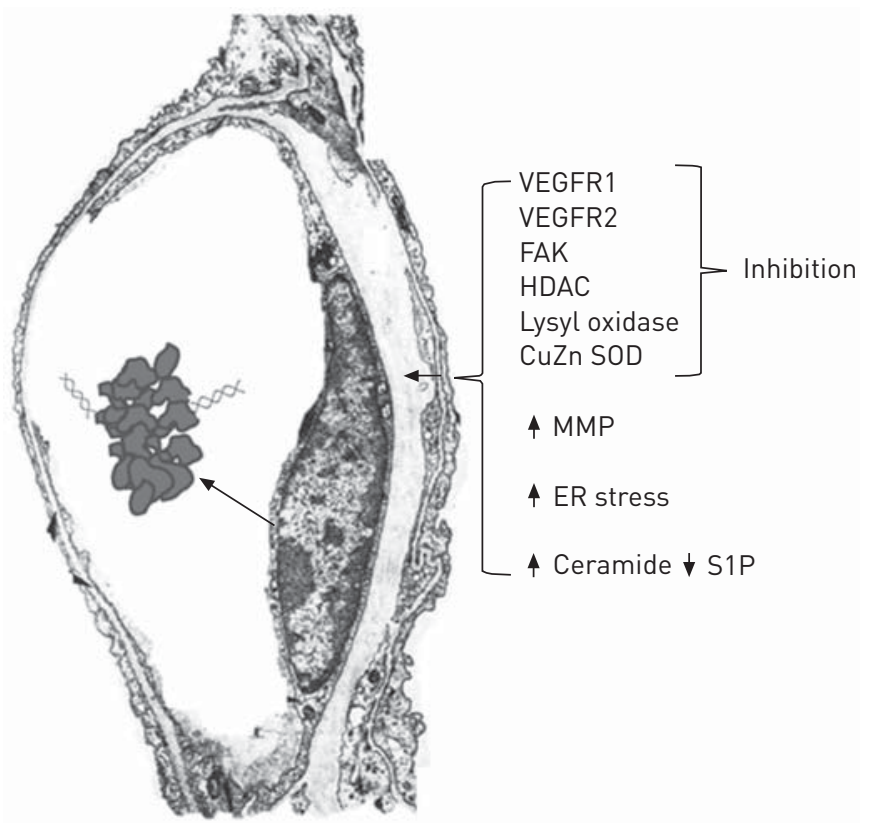

FIGURE 1 Electron microscopy image of a single lung capillary with the large nucleus and thin, stretched out cell body. Potentially cell damaging drug targets are receptor kinases and enzymes. Receptor kinases may be inhibited and enzymes may become activated (e.g. metalloproteinase) or inhibited (e.g. lysyl oxidase and superoxide dismutases). Vascular endothelial growth factor (VEGF) signalling via its membrane and nuclear receptors, when intact, and the sphingosine-1 phosphate (S1P)/ceramide balance negative cell survival as part of the adult lung structure maintenance programme. The agglomeration in the capillary lumen depicts nuclear fragments and the free DNA generated during the course of apoptosis. VEGFR: VEGF receptor; FAK: focal adhesion kinase; HDAC: histone deacetylase; SOD: superoxide dismutase; MMP: matrix metalloproteinase; ER: endoplasmic reticulum. 
shown in the lung tissue specimens in the context of inflammation, we wondered whether HDACs were also participating in the work of the lung structure maintenance programme, and whether HDAC inhibition causes, by compromising gene expression, emphysema. Indeed, the nonspecific HDAC inhibitor trichostatin A, when administered daily, caused emphysema in rats within a few weeks [25]. Airspace enlargement was associated with apoptosis, suppressed expression of hypoxia-inducible factor (HIF)-1 $\alpha$, VEGF and lysyl oxidase (LOX), while the lung tissue expression of p53 and of miR34a was increased [25]. Gene silencing of HDAC2 in cultured human pulmonary microvascular endothelial cells suppressed the expression of HIF-1 $\alpha$ and VEGF [25]. Thus, HDAC inhibition can result in the dampening of inflammation, but also compromise lung cell growth.

In addition to protein kinases and epigenetic controllers involved in the transcriptional control of many fundamental processes of cell biology, such as senescence and autophagy, sphingolipids have been invoked to play a role in the pathobiology of emphysema [26, 27]; for example, ceramide levels are increased in lung tissue lipid extracts from individuals with smoking-induced emphysema [26]. Balanced actions of sphingosine-1 phosphate (S1P) and ceramides, also referred to as the sphingolipid rheostat, may participate in the lung structure maintenance as a controller of apoptosis [28]. The current understanding is that S1P is pro-angiogenic and anti-apoptotic whereas ceramides trigger apoptosis [28]. The synthetic retinoid $\mathrm{N}$ - $(4-$ hydroxyphenyle) retinamide (4-HPR, fenretinide) is currently being investigated as an anticancer agent [29]; its pro-apoptotic activity is thought to be due to ceramide generation [30]. Given the known activation of ceramide synthesis by fenretinide, we showed that treatment of adult rats with fenretinide caused lung airspace enlargement which was prevented by concomitant treatment with intraperitoneal administered S1P. Fentretinide-induced emphysema was associated with an increase in the number of caspase $3^{+}$cells and a reduced expression of HIF-1 $\alpha$, VEGF and HDAC2 proteins, suggesting that de novo synthesis of ceramide affected the expression of the critically important transcription factor HIF-1 $\alpha$ [31, 32], as previously observed after treatment of animals with the HDAC inhibitor (see above).

It has been recognised for many years that steroids cause apoptosis of lymphocytes and eosinophils and that they can activate matrix metalloproteinase (MMP). It has also been well documented that glucocorticoids can impair post-natal lung development [33,34]. With this information CHOE et al. [35] treated adult rats with a daily dose of methylprednisolone $\left(2 \mathrm{mg} \cdot \mathrm{kg}^{-1}\right)$ and detected airspace enlargement after 4 weeks of treatment. The steroid treatment had increased the lung tissue activity of MMP-9 and the emphysematous enlargement induced by steroid treatment was prevented by a pan MMP-inhibitor [35]. Dexamethasone induces apoptosis of cultured human lens epithelial cells [36] and chondrocytes [37], and triamcinolone causes skeletal muscle cell apoptosis [38]. Thus, while it is accepted that steroids can be cytotoxic and facilitate the development of osteoporosis, there is no published information that relates to the effects of high-dose steroids on the lung parenchyma of patients that have been treated with systemically administered steroids for prolonged periods of time.

Finally, acrolein; this highly reactive aldehyde is not a drug and acrolein is discussed here in the context of its potentially synergistic toxicity. Acrolein is one of the several thousand chemicals that are inhaled by smokers. Depending on the brand of the cigarette $200-400 \mu \mathrm{g}$ of this volatile aldehyde are inhaled with the smoke of a single cigarette [39]. However, acrolein is also endogenously generated during inflammation, produced via myeloperoxidase-mediated degradation of threonine and amine oxidase-mediated degradation of spermine and spermidine [40,41]. Of potential clinical importance, acrolein is also a metabolite of cyclophosphamide [42]. The aggressive aldehyde circulates in the blood and is excreted in the urine. Recently, it has been shown that systemically administered acrolein generates endoplasmic reticulum stress and emphysema in adult rats [43], probably because of the induction of endothelial cell apoptosis [44, 45]. Whether cyclophosphamide treatment of patients causes emphysematous lung tissue destruction is unknown (table 1).

Dietary habits or nutritional deficiencies are another area of potential concern. We know that the trace metal copper is essential for the proper function of a number of enzymes. The functions of CuZn superoxide dismutase and LOX, the enzyme critically involved in collagen and elastin fibre crosslinking, are well understood [23]. Copper is required for angiogenesis [46] and the mutated copper transporter gene Atp7a is responsible for congenital emphysema in children with Menkes disease [47]. There is an animal model of this disease, the Blotchy mouse, which carries a mutation of this particular gene and spontaneously develops emphysema [48]. Dietary copper deficiency is rather common [49, 50] and copper measurements of exhaled air condensates obtained from patients with COPD suggest some degree of copper deficiency in these patients [51]. Mizuno et al. [23] fed adult rats a copper-depleted diet and treated the animals with a $\mathrm{Cu}^{++}$- chelator; they found that the animals developed profound emphysema and occasionally subpleural blebs. In these lungs, HIF- $1 \alpha$ activity and VEGF expression were decreased and many cells stained positive for cleaved caspase 3, a marker of apoptosis. Thus, interestingly in these 
TABLE 1 Drugs that experimentally generate emphysematous lung destruction

\section{Sugen 5416 \\ Trichostatin A \\ Fenretinide \\ Cyclophosphamide}

Tetrathiomolybdate

High-dose steroid therapy

\author{
VEGF receptor tyrosine kinase inhibition \\ Histone deacetylase inhibitor \\ Ceramide generation \\ Acrolein generation \\ Copper chelator \\ Cytotoxicity
}

Anti-angiogenic

Effect on gene expression and cell growth

Oxidant stress and apoptosis induction

Endoplasmic reticulum stress and endothelial cell apoptosis

Decreased activity of CuZn SOD and lysyl oxidase Induction of apoptosis and activation of metalloproteinase

VEGF: vascular endothelial growth factor; SOD: superoxide dismutase.

experimental studies $\mathrm{Cu}^{++}$depletion and chelation reproduced the findings observed in mice carrying the mutation of the $\mathrm{Cu}^{++}$transporter gene $[48,52]$.

To conclude, we believe that the adult lung structure is not stable and can be attacked from the environment via inhalation, but also via the circulation. Experimentally, both nutritional deficiencies and drugs which induce apoptosis cause lung airspace enlargement without apparent inflammation. VEGF receptor inhibitors, HDAC inhibitors and drugs which offset the S1P/ceramide rheostat and cyclophosphamide (via acrolein) are examples of drugs that may cause emphysema in susceptible patients. Susceptible individuals may be smokers, ex-smokers and malnourished patients. Drugs or dietary deficiencies may perhaps by themselves have a limited impact on the normal lung structure, but their impact may become synergistic and relevant in smokers and immunecompromised patients or in patients with $\alpha_{1}$-antitrypsin deficiency [53]. Understandably, such a concept is in conflict with the opinion of investigators that do not believe that structural cell apoptosis is the "primary initiator of emphysema and that airspace enlargement in apoptotic models of emphysema rather reflects acute lung injury and changes in surface tension" [54]. Finally, it is not our intention to minimise the complexity of a group of diseases that we consider under the name COPD/ emphysema or the under recognised entity of emphysema combined with pulmonary fibrosis [55] which has been observed so far only in smokers.

\section{References}

1 Camus P, Fanton A, Bonniaud P, et al. Interstitial lung disease induced by drugs and radiation. Respiration 2004; 71: 301-326.

2 Bellamy EA, Husband JE, Blauquiere RM, et al. Bleomycin-related lung damage: CT evidence. Radiology 1985; 156: $155-158$.

3 Dean PJ, Groshart KD, Porterfield JG, et al. Amiodarone-associated pulmonary toxicity. A clinical and pathologic study of eleven cases. Am J Clin Pathol 1987; 87: 7-13.

4 Sederholm C, Hillerdal G, Lamberg K, et al. Phase III trial of gemcitabine plus carboplatin versus single-agent gemcitabine in the treatment of locally advanced or metastatic non-small-cell lung cancer: the Swedish Lung Cancer Study Group. J Clin Oncol 2005; 23: 8380-8388.

5 Wu R, Li R. Propylthiouracil-induced autoimmune syndromes: 11 case report. Rheumatol Int 2012; 32: 679-681.

6 Lee JY, Chung JH, Lee YJ, et al. Propylthiouracil-induced nonspecific interstitial pneumonia. Chest 2011; 139: 687-690.

$7 \quad$ Schwarz MI, King TE. Intersititial Lung Disease. Shelton, People’s Medical Publishing House, 2011.

8 Camus P, Costabel U. Drug-induced respiratory disease in patients with hematological diseases. Semin Respir Crit Care Med 2005; 26: 458-481.

9 De Sanctis A, Taillade L, Vignot S, et al. Pulmonary toxicity related to systemic treatment of nonsmall cell lung cancer. Cancer 2011; 117: 3069-3080.

10 Eisner MD, Anthonisen N, Coultas D, et al. An official American Thoracic Society public policy statement: novel risk factors and the global burden of chronic obstructive pulmonary disease. Am J Respir Crit Care Med 2010; 182: 693-718.

11 Coxson HO, Chan IH, Mayo JR, et al. Early emphysema in patients with anorexia nervosa. Am J Respir Crit Care Med 2004; 170: 748-752.

12 Davison AG, Fayers PM, Taylor AJ, et al. Cadmium fume inhalation and emphysema. Lancet 1988; 1: 663-667.

13 Taraseviciene-Stewart L, Voelkel NF. Molecular pathogenesis of emphysema. J Clin Invest 2008; 118: 394-402.

14 Tuder RM, Petrache I. Pathogenesis of chronic obstructive pulmonary disease. J Clin Invest 2012; 122: 2749-2755.

15 Fong TA, Shawver LK, Sun L, et al. SU5416 is a potent and selective inhibitor of the vascular endothelial growth factor receptor (Flk-1/KDR) that inhibits tyrosine kinase catalysis, tumor vascularization, and growth of multiple tumor types. Cancer Res 1999; 59: 99-106.

16 Kasahara Y, Tuder RM, Taraseviciene-Stewart L, et al. Inhibition of VEGF receptors causes lung cell apoptosis and emphysema. J Clin Invest 2000; 106: 1311-1319.

17 Voelkel NF, Vandivier RW, Tuder RM. Vascular endothelial growth factor in the lung. Am J Physiol Lung Cell Mol Physiol 2006; 290: L209-L221.

18 Tang K, Rossiter HB, Wagner PD, et al. Lung-targeted VEGF inactivation leads to an emphysema phenotype in mice. J Appl Physiol 2004; 97: 1559-1566. 
19 Kieran MW, Supko JG, Wallace D, et al. Phase I study of SU5416, a small molecule inhibitor of the vascular endothelial growth factor receptor (VEGFR) in refractory pediatric central nervous system tumors. Pediatr Blood Cancer 2009; 52: 169-176.

20 Bocci G, Falcone A, Fioravanti A, et al. Antiangiogenic and anticolorectal cancer effects of metronomic irinotecan chemotherapy alone and in combination with semaxinib. Br J Cancer 2008; 98: 1619-1629.

21 Kaikai S, Yuchen S, Lili J, et al. Critical role of c-Jun N-terminal kinase in regulating bFGF-induced angiogenesis in vitro. J Biochem 2011; 150: 189-197.

22 Shen K, Ji L, Lu B, et al. c-Jun N-terminal kinase mediated VEGFR2 sustained phosphorylation is critical for VEGFA-induced angiogenesis in vitro and in vivo. Cell Biochem Biophys 2012; 64: 17-27.

23 Mizuno S, Yasuo M, Bogaard HJ, et al. Copper deficiency induced emphysema is associated with focal adhesion kinase inactivation. PLoS One 2012; 7: e30678.

24 Ito K, Ito M, Elliott WM, et al. Decreased histone deacetylase activity in chronic obstructive pulmonary disease. N Engl J Med 2005; 352: 1967-1976.

25 Mizuno S, Yasuo M, Bogaard HJ, et al. Inhibition of histone deacetylase causes emphysema. Am J Physiol Lung Cell Mol Physiol 2011; 300: L402-L413.

26 Petrache I, Natarajan V, Zhen L, et al. Ceramide upregulation causes pulmonary cell apoptosis and emphysemalike disease in mice. Nat Med 2005; 11: 491-498.

27 Medler TR, Natarajan V, Zhen L, et al. Apoptotic sphingolipid signaling by ceramides in lung endothelial cells. Am J Respir Cell Mol Biol 2008; 38: 639-646.

28 Mandala SM, Thornton R, Tu Z, et al. Sphingoid base 1-phosphate phosphatase: a key regulator of sphingolipid metabolism and stress response. Proc Natl Acad Sci USA 1998; 95: 150-155.

29 Bruno S, Ghiotto F, Tenca C, et al. N-(4-hydroxyphenyl)retinamide promotes apoptosis of resting and proliferating B-cell chronic lymphocytic leukemia cells and potentiates fludarabine and ABT-737 cytotoxicity. Leukemia 2012; 26: 2260-2268.

30 Mata NL, Lichter JB, Vogel R, et al. Investigation of oral fenretinide for treatment of geographic atrophy in agerelated macular degeneration. Retina 2013; 33: 498-507.

31 Yasuo M, Mizuno S, Allegood J, et al. Fenretinide causes emphysema, which is prevented by sphingosine 1-phoshate. PLoS One 2013; 8: e53927.

32 Yasuo M, Mizuno S, Kraskauskas D, et al. Hypoxia inducible factor-1 $\alpha$ in human emphysema lung tissue. Eur Respir J 2011; 37: 775-783.

33 Flomerfelt FA, Briehl MM, Dowd DR, et al. Elevated glutathione S-transferase gene expression is an early event during steroid-induced lymphocyte apoptosis. J Cell Physiol 1993; 154: 573-581.

34 Matsukura M, Yamada H, Yudate T, et al. Corticosteroid-induced apoptosis of eosinophils in atopic dermatitis patients. J Clin Lab Immunol 1996; 48: 109-122.

35 Choe KH, Taraseviciene-Stewart L, Scerbavicius R, et al. Methylprednisolone causes matrix metalloproteinasedependent emphysema in adult rats. Am J Respir Crit Care Med 2003; 167: 1516-1521.

36 Petersen A, Carlsson T, Karlsson JO, et al. Effects of dexamethasone on human lens epithelial cells in culture. Mol Vis 2008; 14: 1344-1352.

37 Nakazawa F, Matsuno H, Yudoh K, et al. Corticosteroid treatment induces chondrocyte apoptosis in an experimental arthritis model and in chondrocyte cultures. Clin Exp Rheumatol 2002; 20: 773-781.

38 Lee MC, Wee GR, Kim JH. Apoptosis of skeletal muscle on steroid-induced myopathy in rats. J Nutr 2005; 135: 1806S-1808S.

39 Jermini C, Weber A, Grandjean E. [Quantitative determination of various gas-phase components of the side-stream smoke of cigarettes in the room air as a contribution to the problem of passive-smoking (author's transl)]. Int Arch Occup Environ Health 1976; 36: 169-181.

40 Igarashi K, Ueda S, Yoshida K, et al. Polyamines in renal failure. Amino Acids 2006; 31: 477-483.

41 Stevens JF, Maier CS. Acrolein: sources, metabolism, and biomolecular interactions relevant to human health and disease. Mol Nutr Food Res 2008; 52: 7-25.

42 Liu F, Li XL, Lin T, et al. The cyclophosphamide metabolite, acrolein, induces cytoskeletal changes and oxidative stress in sertoli cells. Mol Biol Rep 2012; 39: 493-500.

43 Kitaguchi Y, Taraseviciene-Stewart L, Hanaoka M, et al. Acrolein induces endoplasmic reticulum stress and causes airspace enlargement. PLoS One 2012; 7: e38038.

44 Misonou Y, Asahi M, Yokoe S, et al. Acrolein produces nitric oxide through the elevation of intracellular calcium levels to induce apoptosis in human umbilical vein endothelial cells: implications for smoke angiopathy. Nitric Oxide 2006; 14: 180-187.

45 Bein K, Leikauf GD. Acrolein - a pulmonary hazard. Mol Nutr Food Res 2011; 55: 1342-1360.

46 He W, James Kang Y. Ischemia-induced copper loss and suppression of angiogenesis in the pathogenesis of myocardial infarction. Cardiovasc Toxicol 2013; 13: 1-8.

47 Grange DK, Kaler SG, Albers GM, et al. Severe bilateral panlobular emphysema and pulmonary arterial hypoplasia: unusual manifestations of Menkes disease. Am J Med Genet A 2005; 139A: 151-155.

48 Hunt DM. Primary defect in copper transport underlies mottled mutants in the mouse. Nature 1974; 249: 852-854.

49 Disilvestro R, ed. Handbook of minerals as nutritional supplements. Boca Raton, CRC Press, 2005.

50 Lukaski HC, Johnson PE. Dietary copper $(\mathrm{Cu})$ at the recommended intake decreases muscle cytochrome $\mathrm{c}$ oxidase (CCO) activity and alters metabolic responses during exercise in men. FASEB J 2005; 19: A982.

51 Mutti A, Corradi M, Goldoni M, et al. Exhaled metallic elements and serum pneumoproteins in asymptomatic smokers and patients with COPD or asthma. Chest 2006; 129: 1288-1297.

52 Ranga V, Grahn D, Journey TM. Morphologic and phenotypic analysis of an outcross line of blotchy mouse. Exp Lung Res 1983; 4: 269-279.

53 Alam S, Li Z, Janciauskiene $\mathrm{S}$, et al. Oxidation of $\mathrm{Z}$ alphal-antitrypsin by cigarette smoke induces polymerization: a novel mechanism of early-onset emphysema. Am I Respir Cell Mol Biol 2011; 45: 261-269.

54 Mouded M, Egea EE, Brown MJ, et al. Epithelial cell apoptosis causes acute lung injury masquerading as emphysema. Am J Respir Cell Mol Biol 2009; 41: 407-414.

55 Cottin V, Nunes H, Brillet PY, et al. Combined pulmonary fibrosis and emphysema: a distinct underrecognised entity. Eur Respir J 2005; 26: 586-593. 